\title{
La métallurgie du fer avant le haut fourneau dans le Maine (Mayenne, Orne, Sarthe)
}

\section{Florian Sarreste}

\section{(QpenEdition Journals}

Édition électronique

URL : http://journals.openedition.org/adlfi/7378

ISSN : 2114-0502

Éditeur

Ministère de la culture

Référence électronique

Florian Sarreste, «La métallurgie du fer avant le haut fourneau dans le Maine (Mayenne, Orne, Sarthe) », ADLFI. Archéologie de la France - Informations [En ligne], Basse-Normandie, mis en ligne le 01 mars 2007, consulté le 20 avril 2019. URL : http://journals.openedition.org/adlfi/7378

Ce document a été généré automatiquement le 20 avril 2019

(c) Ministère de la Culture et de la Communication, CNRS 


\title{
La métallurgie du fer avant le haut fourneau dans le Maine (Mayenne, Orne, Sarthe)
}

\author{
Florian Sarreste
}

Date de l'opération : 2007 (PT)

Inventeur(s) : Sarreste Florian (BEN)

L'année 2007 était la troisième et dernière année d'un programme pluriannuel de prospection thématique portant sur les vestiges de la sidérurgie ancienne dans le Maine. Cette recherche, entamée dans le cadre d'un DEA, était au départ centrée sur l'agglomération antique de Jublains (Mayenne). Les investigations menées dans le cadre d'une thèse de doctorat de l'université de Tours, engagée sous la direction d'Alain Ferdière en octobre 2004, ont été étendues à l'ensemble du département de la Mayenne et à une partie de l'Orne et de la Sarthe.

L'application systématique de méthodes de recherches documentaires (bibliographie, microtoponymie, examen des photographies aériennes verticales de l'IGN, enquête orale et écrite) ont permis d'établir un inventaire informatisé comptant à l'heure actuelle plus de huit cents indices de sites dans la zone d'étude. Les vérifications de terrain et les prospections en milieu boisé menées en collaboration avec Michel Hubert, ont permis de visiter plus des deux tiers de ces indices et d'enregistrer près de cinq cents sites liés à la métallurgie du fer. Ces travaux ont donné lieu à la déclaration de quatre cent soixantetreize sites auprès des services régionaux de l'Archéologie, dont quatre-vingt-neuf pour l'année 2007.

Ce travail arrive maintenant à son terme. Nous possédons une cartographie précise et la plus exhaustive possible des sites de production du fer ancien de la partie occidentale de la province du Maine. Quatorze zones de production ont été cernées. Malgré le faible nombre de sites datés avec certitude (moins de $15 \%$ ), il apparait que la période romaine est celle de l'apogée de la production du fer par la méthode directe dans la région. 
Toutefois, la diachronie des activités est très forte. Le plus ancien vestige de la métallurgie du fer est une scorie piégée découverte à l'orée de la forêt de Sillé (Sarthe) datée par radiocarbone des IV ${ }^{\mathrm{e}} \mathrm{s}$. av. J.-C. et III ${ }^{\mathrm{e}} \mathrm{s}$. av. J.-C. À l'opposé, dans les zones de la Ferrière-aux-Étangs (Orne) et du sud de la Mayenne, la majorité des amas de réduction est attribuable à l'époque médiévale.

L'analyse et la synthèse de ces trois années de travaux de terrain feront l'objet d'un mémoire de thèse qui devrait être soutenu avant la fin de l'année 2008.

SARRESTE Florian

INDEX

operation Prospection thématique (PRT)

Index chronologique : âge du Fer, Empire romain, Moyen Âge*

Thèmes : carte archéologique, enregistrement-diffusion, habitat groupé, inventaire, métallurgie, méthodologie, outil documentaire, photographie aérienne, scories, sidérurgie

Index géographique : Basse-Normandie, Orne (61), Ferrière-aux-Étangs

\section{AUTEURS}

FLORIAN SARRESTE

BEN 